УДК 621.89.012.7

A. G. Zheleznov ${ }^{1}$, V. A. Godlevskiy ${ }^{I}$, E. V. Berezina ${ }^{1}$, A. I. Smirnova ${ }^{1}$, N. N. Rozhkova ${ }^{2}$, N. V. Usol'tseva ${ }^{1}$

\title{
ON PREDICTION OF TRIBOTECHNICAL CHARACTERISTICS OF LUBRICANTS USING POLARIZATION TRIBOMETRY METHOD
}

\author{
${ }^{1}$ Ivanovo State University, 39 Ermak St., Ivanovo, 153025, Russia \\ E-Mail: antonzhelezn@gmail.com \\ ${ }^{2}$ Institute of Geology, Karelian Research Centre, Russian Academy of Sciences, \\ 11 Pushkinskaya St., Petrozavodsk, 185910, Russia
}

The experimental data on correlation results of classic tribometric and polarization tribometric experiments are given. Using models of epitropic liquid crystalline layers of finite constant and infinite high viscosity a dimensional type of structural order in the investigated lubrication layer has been determined. The experimental method is based on the analysis of the plane-polarized radiation passed through the lubrication layer during the process of stationary shear flow.

Key words: epitropic liquid crystalline layer, mesogen, lubricating materials, lubrication layer, polarizing tribometer, anisotropy, plane-polarized radiation, stationary shear, supramolecular structure, triboactive additives, birefringence.

DOI: $10.18083 /$ LCAppl.2017.2.86

\section{А. Г. Железнов ${ }^{1}$ В. А. Годлевский ${ }^{1}$ Е. В. Берёзина ${ }^{1}$, А. И. Смирнова ${ }^{1}$, Н. Н. Рожккова ${ }^{2}$ Н. В. Усольцева \\ К ВОПРОСУ О ПРОГНОЗИРОВАНИИ ТРИБОТЕХНИЧЕСКИХ СВОЙСТВ СМАЗОЧНЫХ МАТЕРИАЛОВ МЕТОДОМ ПОЛЯРИЗАЦИОННОЙ ТРИБОМЕТРИИ}

\author{
${ }^{1}$ Ивановский государственный университет, \\ ул. Ермака, д. 39, 153025 Иваново, Россия. E-mail: antonzhelezn@gmail.com \\ ${ }^{2}$ Институт геологии Карельского научного центра РАН, \\ ул. Пушкинская, д. 11, 185910 Петрозаводск, Россия
}

Приведены результаты экспериментов по выявлению корреляции результатов классического трибометрического и поляризачионно-трибометрического экспериментов. С использованием моделей эпитропных жидкокристаллических слоев конечной постоянной и бесконечно большой вязкости идентифицирован объемный тип структурной упорядоченности в исследованном смазочном слое. Основа экспериментального метода - анализ плоскополяризованного лазерного излучения, прошедшего сквозь смазочный слой непосредственно в процессе стационарного сдвигового течения.

Ключевые слова: эпитропный жидкокристаллический слой, мезоген, смазочные материаль, смазочный слой, поляризаичонный трибометр, анизотропия, плоско-поляризованное излучение, стационарный сдвиговый процесс, надмолекулярная структура, трибоактивные присадки, двулучепреломление.

(C) Zheleznov A.G., Godlevskiy V.A., Berezina E.V., Smirnova A.I., Rozhkova N. N., Usol’tseva N.V., 2017 


\section{Introduction}

Interrelation of the structure state with the lubrication compositions characteristics and determining physical-chemical processes impacting the lubrication activity still belong to not entirely resolved challenges in the field of lubrication materials tribology [1]. Impossibility to directly observe and measure in the tribocontact zone remains a significant obstacle for more profound understanding of the phenomena in question and, hence, for creating theoretical models of the lubrication process. In this relation the task of developing new methods for lubrication layers' investigation allowing to describe processes in friction zone, if only at a qualitative level, taking place not only in the lubrication material itself but also close to rubbing surfaces is still a burning issue. This task has not been resolved so far due to the fact that in order to study characteristics of solid bodies contacting with the lubrication media the friction process should be stopped and tribocontact disconnected. In this approach, only surface characteristics can be studied irrelatively to the friction process and not characteristics of tribocoupling as a whole.

In the work [2], the author raises a point of how friction conditions influence the structural state of the lubrication compositions giving powerful proofs that changing flow conditions leads to rebuilding the lubrication material structure in the clearance between the tribocoupling surfaces. However, the author does not take into account that the lubrication material structure especially in small clearances is determined not only by hydrodynamics but also by force interaction of active components of lubrication materials with friction surfaces. The impact of such interaction on the lubrication effect must be the higher the more adsorptionally active and less uneven the tribocontact surfaces are. The authors of work [3] emphasize that the lubrication activity of layers of adsorptional origin is mainly influenced by the orientation degree of molecules of lubrication compositions active components close to friction surfaces. The analysis of the given facts allows to conclude that the determining role in different lubrication modes can belong both to hydrodynamic conditions of the shear flow and orientation order of lubrication layers in surface forces field [4].

To identify the impact of molecular orientation effects over the rheological and tribotechnical characteristics of lubrication layers we have offered to use tribometers of a special design. Namely, these are polarization tribometers. The basic principle of these devices lies in analyzing the polarized light having interacted with the lubrication material under the shear conditions.

Besides, these devices were equipped with photofixing elements allowing to get images of mesomorphic lubrication layers right in the friction process in incremental relative movement of tribocoupling surfaces [1] or in circuit path [5].

The first device of such kind was a polarization tribometer developed on the basis of a standard microtribometer allowing not only to measure the friction temperature but to determine the texture of anisotropic boundary lubrication layers in different loads. In the work of P. Oswald and P. Piranski [5], the behavior of nematic liquid crystal placed into shear conditions was described. In their experiment the rotary moment of viscous friction forces influencing the main orientation of molecule axes was determined. It is worth noting that impossibility to implement stationary shear conditions and set the value of clearance between the rubbing surfaces can be considered as weak points of the methods described above.

We have offered an approach [6], which allows to investigate tribosystem behavior under isothermal conditions of stationary friction with the controlled working clearance size. We have developed a device named "polarization tribometer", which allows solving the task of observing the tribosystem under the stationary friction conditions. The working principle of the device is based on the polarization light analysis, which is traditionally used for investigating anisotropic partially ordered media. This method provides accurate information about dimensional orientation of molecules in mesomorphic media. The present work develops the concept of polarizationoptical investigations of partially ordered samples and identifying the interaction of tribotechnical and optical characteristics of lubrication layers in the process of stationary friction.

\section{Work objective}

The work objective lies in experimental grounding of the new investigation method of supramolecular structure of lubrication layers containing anisometric triboactive components posses- 
sing the ability to form both boundary and dimensional structurally ordered phases influencing the lubrication effect by setting the correlation between the data of classic tribometric and polarization-tribometric experiments.

\section{Problem Statement}

We assume that the appearance of orientation order in lubrication layers positively influences the lubrication effect. In this case, it is very important to get a criterion measuring the degree of order, which determines the layer's anisotropy. The last one, in its turn, impacts the radiation intensity having passed through the lubrication layer. The layer's light transmission is evidently determined by mechanical tensions appearing in it under conditions of the stationary shear. In our device, we have realized the "disk-disk" friction scheme in which the disks rub each other with their front surfaces. In this case, the average shear tensions value is proportional to the rotational moment created by the motor for maintaining stationary turning. The rotational moment is registered by the tribometer measuring system.

The intensity of the layer's light transmission as a parameter showing the level of its order can be considered as a certain integral characteristic determined by the average parameter of the molecules orientation under the conditions of flow absence and certain orientation parameter of the flow. The latter parameter depends on the velocity and radial coordinate at which the optical response of the system is registered. The lubrication material with triboactive additives of the structural activity can have a non-zero parameter of anisotropy when there is no shear. However, trying to follow the continuity of arguments but from considerations of simplicity let us assume that at working temperatures of the tribocontact this parameter equals zero. The anisotropy caused by the orientation effects in the flow will depend on the velocity component in the layer and will provide for double refraction when the originally plane-polarized radiation is passing through the lubrication layer. Let us assume that the level of anisotropy expressed in arbitrary units as an intensity of light transmission of the lubrication material layer reflects the degree of its tribological efficiency as structuring leads to augmenting the lubrication effect [2].

\section{Experimental unit}

Registering all the parameters of the friction process right in the conditions of relative movement of tribocoupling surfaces enhance the accuracy of conclusions to be made out of the experiment data analysis. This principle was put into the basis of the developed polarization tribometer [6,7].

Two optical glasses, one of which is fixed in the cup of tribometer filled by the lubrication material under study and the other one is fixed on the engine's shaft, serve as a friction couple of the tribometer. The moving glass can turn in the measuring cup around the vertical axis with the angle velocity $\omega$ regulated within the range of $20-120 \mathrm{rpm}$. The use of the transparent friction couple is determined by the need to register radiation passed through the lubrication layer. The plane-polarized radiation generated by the laser source passes through the lubrication material layer and is registered by the photo element at the exit from the tribocontact zone.

As follows from the anisotropic media theory, the light spreading in the anisotropic media in question with different velocities is divided into two beams with mutually perpendicular orientation of polarization planes. In this case, between two beams called usual and unusual a phase shift appears and elliptically polarized beam gets out of the sample media. The degree of polarization of this radiation is measured by the analyzer placed between the glasses of friction and photo element located cross-wise in relation to the polarization plane of radiation.

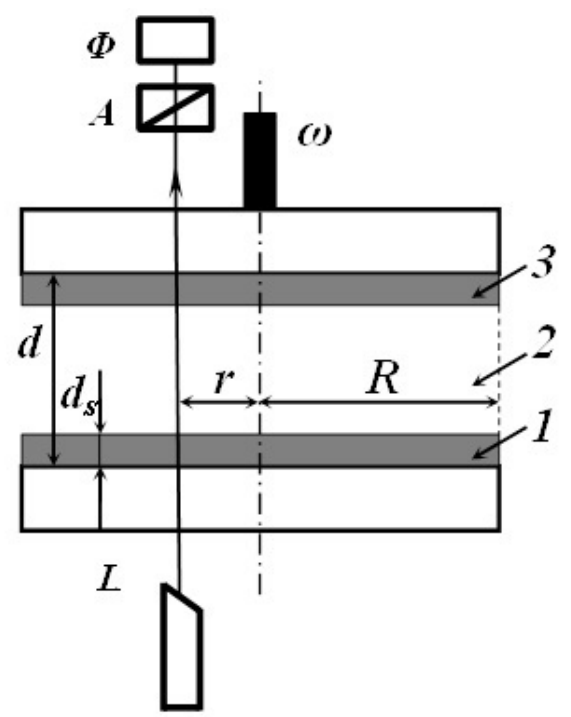

Fig. 1. Working part of the polarization tribometer:

1,3-epitropic liquid crystalline layers (ELC),

2 - dimensional liquid, $L$ - laser, $A$ - polarizer-analyzer, $\Phi$ - photo element 
The optical-mechanical scheme of the measuring part of the tribometer for registering effects of molecular orientation in lubrication layers under conditions of stationary shear can be seen at Fig. 1, where: $d$ is distance between optical windows, $d_{s}$ is thickness of the boundary ordered layer, $r$ is distance from rotation axis to optical measuring zone, $R$ is radius of measuring surfaces.

\section{Theory}

To interpret experiment data and identify the order type of the lubrication layer containing structurally active components we use the results of mathematic simulation: 1) model of rigid layer cut by the flow and 2) model of epitropic liquid crystalline (ECL) layer of constant viscosity. In the context of the present work, we can consider the results of mathematic simulation received both for the ELClayer model of constant viscosity and for the model of rigid cut layer. This is explained by the fact that we have investigated thick layers (thick compared to boundary lubrication layers). That is why we can ignore the boundary order type in this case.

The rigid cut layer (CL) model with triboactive additives of structural activity [7] suggests infinitely large value of viscosity $\eta_{s}$ of the ordered epitropic liquid crystalline layer. In addition, the liquid phase with dimensional viscosity $\eta_{s}$ moves between friction surfaces in the clearance with width

$$
h=d-2 d_{s} \text {. }
$$

With these assumptions as shown in [11], the light transmission intensity of the lubrication layer $I$ is described by the following formula:

$$
I=I_{0} \sin ^{2} \frac{\pi V D_{0} \eta_{0}}{\lambda}\left(1+\frac{\left(d-2 d_{s}\right)^{2}}{6 r^{2}}\right),
$$

where $I_{0}$ is the intensity of light flow falling on the $\mathrm{CL}, D_{0}$ is dynamo-optical constant in the model of the cut layer, $\lambda$ is radiation wave length, $V=\omega r$ is velocity of relative movement of friction surfaces at a distance $r$ from the rotation axis.

Expression (2) can serve as a qualitative value of the order degree in the lubrication layer. It is worth noting that the CL model can be applied in the cases of small normal and shearing tensions and adsorptionally active surfaces able to form narrow solid boundary lubrication layers strongly connected to the surface, which are mainly presented by chemically adsorbed structures. These arguments have led us to consider one more model [11], where we assumed a constant finite value of boundary layer viscosity.

The model of epitropic liquid crystalline layer of constant viscosity [10] suggests that the lubrication material placed between friction surfaces forms boundary layers of thickness $d_{s}$ having viscosity ratio $\eta_{s}$. There is a layer of dimensional liquid between them with thickness $h$ and viscosity $\eta_{0}$. The model allowed determining the light transmission intensity of the layer for two important cases from the application point of view:

1. The case of thick layers $d>>d_{s}$ :

$$
I=I_{0} \sin ^{2} \frac{\pi V \bar{D} \eta_{0}}{\lambda}\left(1+\frac{d^{2}}{6 r^{2}}\right) .
$$

2. The case of thin layers $d \sim d_{s}$ :

$$
I=I_{0} \sin ^{2}\left\{\frac{\pi V \bar{D} \eta_{0}}{\lambda}\left(1-2 \frac{d_{s}}{d}\left(1-\frac{\eta_{s}}{\eta_{0}}\right)\right)\right\},
$$

where $\bar{D}$ is an average value of dynamo-optical constant.

Analysis of dependencies (2), (3) and (4) shows that the growth of the sample shear deformation velocity must lead to the regular changes in light transmission intensity of layers. However, we cannot observe this effect in in-situ experiment as the difference in movements of usual and unusual beams is so insignificant that sines can be decomposed into Maclauren's series using only the first element.

\section{Experimental}

Statements developed in the theoretical section are confirmed by experimental investigation of lubrication layers on the basis of the industrial oil I$20 \mathrm{~A}$ presented in Table. The studied samples are compositions of the I-20A oil with additives cholesterol tridecylate (X-20) and schungite mineral. The dependency of the registered light flow intensity on the sliding velocity is shown at Fig. 2. 
Table. Compositions of the studied samples of lubrication material

\begin{tabular}{|l|c|c|c|c|}
\hline $\begin{array}{c}\text { Arbitrary number and compositions of } \\
\text { samples }\end{array}$ & Oil mass, mg & $\begin{array}{c}\text { Oil mass } \\
\text { percent }\end{array}$ & $\begin{array}{c}\text { Additive mass, } \\
\text { mg }\end{array}$ & $\begin{array}{c}\text { Additive mass } \\
\text { percent X-20 } \\
\text { +schungite }\end{array}$ \\
\hline 0- Oil I-20A & 7065.0 & 100 & 0 & 0 \\
\hline 1-Oil I-20A-(X-20-0),2\% & 6437.5 & 98 & 131.5 & 2 \\
\hline 2- Oil I-20A-(X-20-0,005),2\% & 6800,4 & 98 & 138,7 & 2 \\
\hline 3- Oil I-20A-(X-20-0,02),2\% & 6775,0 & 98 & 140,0 & 2 \\
\hline 4-Oil I-20A-(X-20-0,01),2\% & 5876,0 & 98 & 119,9 & 2 \\
\hline
\end{tabular}

The analysis of dependencies between the photo current intensity from rotation velocity and lubrication layer thickness similar to the one shown at Fig. 2 allows to make the following conclusions:

1. Originally isotropic lubrication compositions when applied to the lubrication layer of shear tension become artificially anisotropic as result of Maxwell's orientation effect. The essence of the effect consists of the fact that in solutions containing anisometric components the anisotropy of refraction characteristic appears as a result of long axis predomination of anisometric components molecules.

2. According to the dependency (3), thick lubrication layers in question (in comparison with boundary layers) show the dimensional type of order when the shear tension is applied which is proved by the photo current growth when both the rotation velocity and the lubrication layer thickness grow.

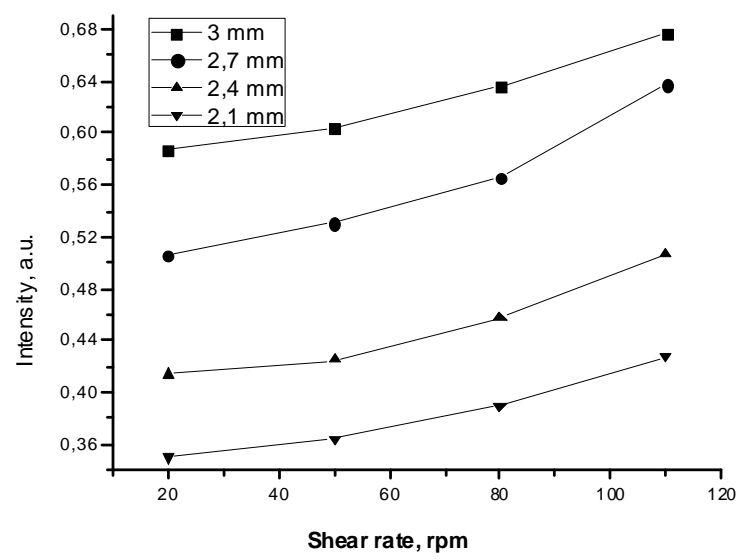

Fig. 2. Dependency of lubrication layer light transmission of composition 4 on the rotation velocity of friction surfaces for lubrication layers of different thickness
To expand the possible application fields of the developed method let us consider the experiment results in measuring friction ratios presented at Fig. 3. Tribotechnical studies of lubrication compositions shown in Table based on mineral oil I-20 A with additives of cholesterol tridecylate of different concentrations were hold on mini-tribometer TAU-1.

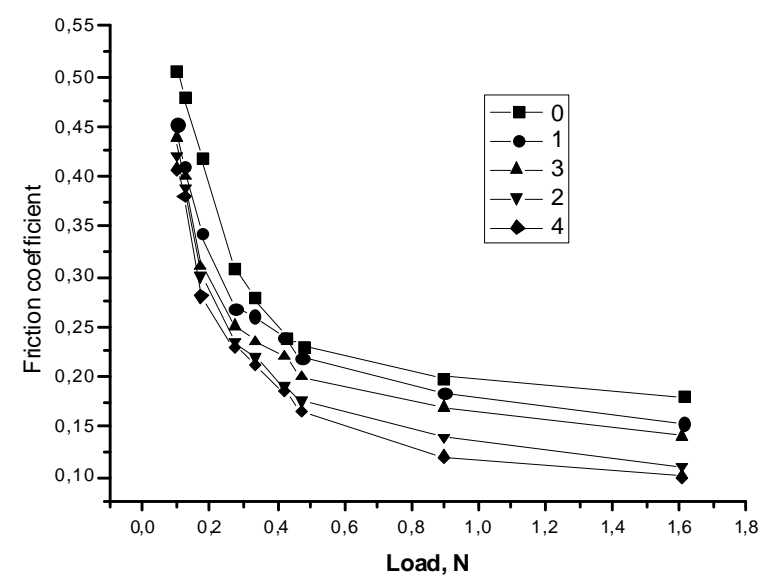

Fig. 3. Dependency of the friction ratio of the compositions in question on tensions in studies hold at the minitribomenter TAU-1: 0, 1, 2, 3, 4 are lubrication compositions codes according to Table

Analysis of the dependency shown on Fig. 3 evidences that the additives allow to decrease the friction ratio value approximately by $30 \%$. Minimal friction ration values are demonstrated by the compositions with maximal light transmission characteristics shown in studies at polarization tribometer. This fact is illustrated at Fig. 4 and 5. Fig. 4 demonstrates a dependency of light transmission intensity of lubrication layers of five studied compositions at a clearance thickness between friction surfaces of polarization tribometer equa- 
ling $2,1 \mathrm{~mm}$ and rotation velocity $20 \mathrm{rpm}$. Fig. 5 presents typical dependency of light transmission intensity of lubrication layers with structurally active components on the rotation velocity of measuring surfaces for the investigated compositions.

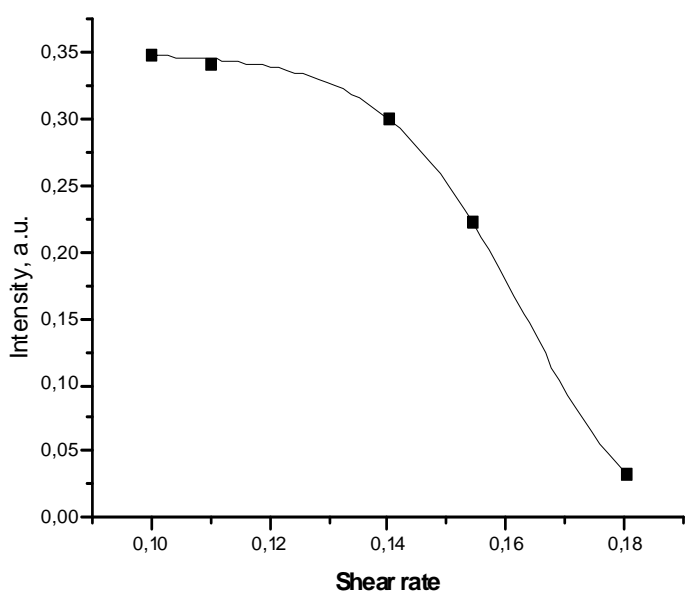

Fig. 4. Dependency of light transmission intensity of lubrication layers on the friction ratio

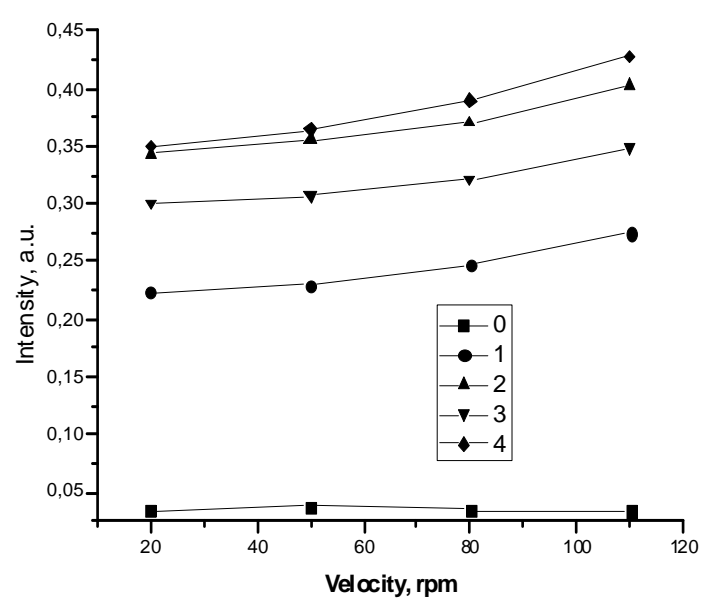

Fig. 5. Dependency of the lubrication layers light transmission intensity on the rotation velocity of measuring surfaces. $0,1,2,3,4$ are codes of lubrication compositions according to Table

It is worth noting that the light transmission growth with simultaneous sliding velocity growth is characteristic only for compositions with anisometric structurally active components. Similar studies of the filtered oil I-20A without additives demonstrate the dependency of the intensity on the velocity presented at Fig. 6, i.e. absence of such dependency within the limits of measurement error.

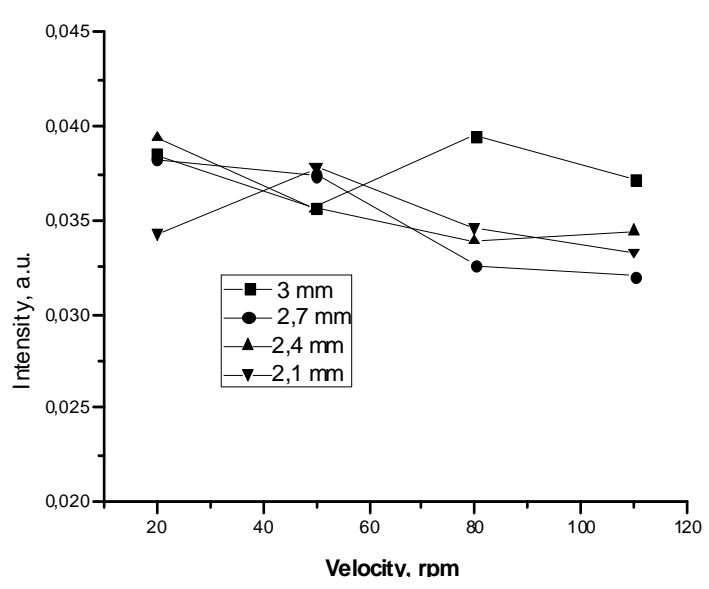

Fig. 6. Dependency of lubrication layers light transmission intensity of the pure oil I-20A on the rotation velocity of the friction surface

This dependency can be explained as following: the pure oil does not contain structurally active components able to be ordered both under the influence of the flow orientation and under the influence of the force field of friction surfaces. As a result, the light passing through the lubrication layer spreads through the isotropic media and interacts with it as with isotropic media.

\section{Conclusions}

Analysis of the data received during the experiments allows to conclude that the lubrication layer light transmission intensity can be considered as a characteristic of both the order degree and tribological efficiency of lubrication layers.

During the polarization-tribometric experiments we have justified the dependencies (2) and (3). Namely, we showed that the light transmission intensity assumed as an order parameter mainly depends on the velocity of mutual movement of solid surfaces. These facts confirm the efficiency of the suggested method when investigating viscosity of Newtonian lubrication compositions. Since changing viscosity of noNewtonian lubrication compositions under the conditions of stationary shear at constant temperature reflects the changes in their dimension, we can conclude that the suggested method is applicable to such media. 
The studied models of thick layers allowed explaining the experiment results when we registered the growth of the lubrication layer light transmission intensity with simultaneous growth of the lubrication layer thickness. Thus, we have identified the dimensional type of order in the layer. The optical layer's response with active molecules determine the functional dependencies of types (2) and (3).

We have one more time demonstrated the correlation between the optical response of the lubrication layer to the shear action and tribological efficiency of the lubrication composition. This fact opens new opportunities for applying the method of polarization tribometry when evaluating tribological efficiency of lubrication compositions.

The work was supported by the Ministry of Education and Science of the Russian Federation (projects No 9.700.2014 and No 16.1037.2017/4.6).

\section{References}

1. Modern tribology: results and prospects / by red. K.V. Frolov. M. : Izdatelstvo LKI, 2014, 480 p. (in Russ.).

2. Kravchik K. Tribological identification of selforganization during friction with lubrication. $\mathrm{PhD}$ thesis. Rostov-on-Don, 2000, 282 p. (in Russ.).

3. Buyanovskiy I.A., Ignatjeva Z.V., Levchenko V.A., Matveenko V.N. Orientational ordering of boundary layers and the lubricity of the oils. Journal of Friction and Wear, 2008, 29 (4), 375-381. (in Russ.).

4. Alisin V.V., Pokid'ko B.V., Roshchin M.N., Silova T.V., Simakova G.A. Studying colloidal greases with hard nanoparticles of aluminium silicates used to reduce wear of steel friction pairs. Journal of Friction and Wear. 2013, 34 (6), 460-465.
5. Oswald P., Pieranski P. Nematic and cholesteric liquid crystals: concepts and physical properties illustrated by experiments. London : Taylor and Francis Group, 2005, 618 p.

6. Godlevskiy V.A., Korsakov M.N., Sandler V.A., Berezina E.V. Polarizing tribometer // International scientific-technical conference «Polymer composites and tribology (POLICOMTRIB-2011)». Gomel, Belarus, 2011. Abstract book. P. 41 (in Russ.).

7. Godlevskiy V.A., Berezina E.V., Zheleznov A.G. Fomichev D.S. Shear-induced anisotropy of lubricating layer. $V$ international symposium on transport science in tribology «Transtribo-2013». St. Petersburg, Russia, 2013. Abstract book. P. 285-289 (in Russ.).

8. Vuks M.F. Electrical and optical properties of molecules and condensed matter. Leningrad : Izd-vo Leningr. Univer., 1984, 334 p.(in Russ.).

9. Berezina E.V., Godlevskiy V.A., Zheleznov A.G. Fomichev D.S. Analytical evaluation of structured lubricating layer. Zhidk. krist. ikh prakt. ispol'z.=. Liq. Cryst. and their Appl., 2014, 14 (1), 74-79 (in Russ.).

10. Altoiz B. A., Aslanov S.K., Butenko A.F. Rotational viscometer for measuring of micron interlayers. Physics of Aero-dispersed systems, 2005, 42, 53-65 (in Russ.).

11. Zheleznov A.G., Berezina E.V., Godlevskiy V.A. An in situ study of lubricant layer morphology. Journal of Friction and Wear, 2015, 36 (3), 223-228.

DOI: $10.3103 / \mathrm{S} 1068366615030150$.

Поступила в редакияю 19.05.2017 2. Received 19 May 2017 